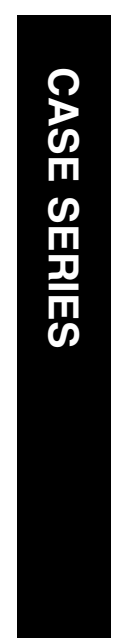

Department of

Ophthalmology, Epsom and St Helier University Hospitals NHS Trust, Sutton Hospital, Sutton, UK

Correspondence:

A Mitra, Wolverhampton Eye Infirmary,

Compton Road,

Wolverhampton,

West Midlands

WV3 9QR, UK

Tel: + 447905956498 .

E-mail: drarijitmitra@

yahoo.com

Received: 7 May 2005

Accepted in revised form:

15 January 2006

Published online: 17 March

2006

The authors do not have any proprietary interest in any product mentioned.

Presented at the 11th Annual Scientific Meeting of MCLOSA 2004, in London.

\title{
Corneal deposits and topical ofloxacin - the effect of polypharmacy in the management of microbial keratitis
}

\begin{abstract}
Purpose To report six cases of corneal deposits after administration of topical ofloxacin in the treatment of bacterial keratitis. Method/result Six cases of microbial keratitis treated with multiple topical medications, including topical ofloxacin, resulted in corneal precipitates and poor wound healing. In five cases, the precipitates resolved with discontinuation of ofloxacin treatment. However, in one patient, some residual deposits persisted following discontinuation of ofloxacin. The cornea epithelialised, but deposits were identified subepithelially. Discussion Fluoroquinolone antibiotic drops have been extensively used in bacterial keratitis because of their ease of availability, broad spectrum of activity, and lack of toxicity. While corneal precipitates have been reported with cases of topical ciprofloxacin and norfloxacin, little has been documented on corneal deposits and topical ofloxacin in the treatment of bacterial keratitis. The predisposing factors resulting in corneal deposits and the role of polypharmacy are important features that may impair epithelialisation. Clinical management should be aimed at reducing the toxic environment and promoting ocular surface stability. Eye (2007) 21, 410-412. doi:10.1038/sj.eye.6702303; published online 17 March 2006
\end{abstract}

Keywords: corneal deposits; ofloxacin; microbial keratitis

\section{Introduction}

Topical fluoroquinolones may be used as monotherapy in the first-line management of corneal ulcers. Topical fluoroquinolones, in particular ciprofloxacin, have been associated with corneal deposits, but little has been reported with topical ofloxacin. Six cases of corneal deposits occurring after the use of intensive topical ofloxacin in the treatment of microbial keratitis are presented. In all cases, multiple topical medications were used in the treatment of the underlying ulcer.

\section{Case reports}

Case 1

A 51-year-old man was treated for an infected corneal abrasion secondary to corneal basement membrane dystrophy. Over a period of 4 days, he had received topical chloramphenicol ointment followed by intensive ofloxacin, cyclopentolate, and subsequently intensive gentamicin. Corneal toxicity and corneal deposits were noted on day 4. Ofloxacin and gentamicin were stopped, treatment was altered, and the deposits largely resolved over 2 weeks.

Case 2

A 73-year-old man with kerato-uveitis was treated with topical ofloxacin, cyclopentolate, and fucithalmic. Dexamethasone was added once the epithelial defect had healed. He developed corneal ofloxacin deposits, as the ulcer epithelialised. Ofloxacin was stopped and the treatment altered. The deposits resolved over the next few weeks.

\section{Case 3}

An 89-year-old man with a corneal ulcer in his blind left eye was treated with intensive topical ofloxacin and cyclopentolate. After 3 days he developed corneal ofloxacin deposits, but the 


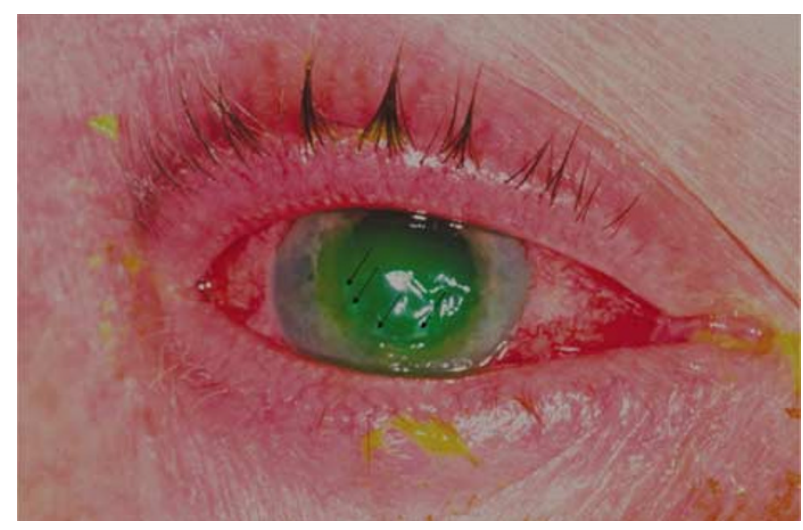

Figure 1 Ofloxacin deposits forming on corneal epithelial defect in Case 1, at presentation.

ulcer showed signs of healing. The treatment was altered and ofloxacin was stopped. The deposits resolved over the next few weeks.

\section{Case 4}

An 84-year-old woman was reviewed having been treated for 1 week with intensive ofloxacin, cefuroxime, and subsequently topical gentamicin for a non-healing corneal ulcer. Corneal toxicity and ofloxacin deposits were noted on the cornea at the periphery of the epithelial defect on day 5 (Figure 1). All topical drops were discontinued for $24 \mathrm{~h}$. Microbiology revealed Moraxella as the causative agent, which was sensitive to chloramphenicol. Superficial keratectomy with corneal scraping was undertaken and the ulcer was treated with preservative-free chloramphenicol and topical steroids. The deposits resolved within a few weeks.

\section{Case 5}

An 82-year-old woman on treatment with latanoprost for glaucoma developed a corneal ulcer in her blind left eye. Intensive topical ofloxacin and cyclopentolate three times a day was initiated. By day 10, the corneal ulcer was healing but ofloxacin deposits appeared on the cornea. Ofloxacin was stopped, and the precipitates resolved quickly with complete healing of the ulcer.

\section{Case 6}

An 83-year-old woman with a history of recurrent herpetic keratitis developed a central corneal ulcer with hypopyon. The patient was treated with ofloxacin drops hourly and cyclopentolate three times a day. Corneal ofloxacin deposits were noted within $48 \mathrm{~h}$. Ofloxacin was discontinued and substituted with topical gentamicin and cefuroxime. The ulcer healed, but central deposits persisted subepithelially.

\section{Discussion}

In the UK, intensive ofloxacin therapy is frequently used as first-line treatment for corneal ulceration. Ofloxacin, a second-generation fluoroquinolone, is used extensively in bacterial keratitis, owing to its ease of availability, broad spectrum of activity, and lack of toxicity. Over the years, ciprofloxacin, norfloxacin, and ofloxacin have been used successfully for the treatment of microbial keratitis. Although there are many reports of crystalline corneal deposits occurring with the use of topical ciprofloxacin $0.3 \%$ and norfloxacin $0.3 \%,^{1-3}$ little has been reported with topical ofloxacin $0.3 \%$. Claerhout et al reported corneal ofloxacin deposits in two children with vernal keratoconjunctivitis. ${ }^{4,5}$ Gatifloxacin, a fourth-generation fluoroquinolone, has been reported to cause intrastromal crystalline deposits with a compromised corneal epithelium, in a similar manner to ciprofloxacin. ${ }^{6}$

The exact cause of these precipitates is unknown, but multidrug therapy and $\mathrm{pH}$ solubility profile may be of importance. Ofloxacin, like other fluoroquinolones, exhibits $\mathrm{pH}$-dependent solubility. In the in vitro tear model, tear drug concentration of ofloxacin remained below solubility at all $\mathrm{pH}$ levels tested $\left(\mathrm{pH}\right.$ 6.4-7.2). ${ }^{7}$ Although, the use of ofloxacin alone does not seem to cause physicochemical changes in the tear film, combination therapy probably alters the $\mathrm{pH}$, resulting in corneal deposits. Combination therapy includes adjuvant medications used such as local anaesthetics and cycloplegics for pain relief as well as topical steroids and other topical antibiotics. Scuderi $e a^{8}$ incubated rabbit corneal epithelial cells (SIRC) for 8-72 $\mathrm{h}$ in the presence of ofloxacin of different concentrations $(1.5,3$, and $6 \mathrm{mg} / \mathrm{ml})$. They found that all concentrations of ofloxacin caused statistically significant dose- and time-dependent reductions in cell viability even after $8 \mathrm{~h}$. After $72 \mathrm{~h}$, there was complete loss of cell viability. Accumulation of large numbers of dead cells and altered general morphology may also account for the ofloxacin deposits.

With reference to the cases presented, at the time of presentation to the corneal service, several of these patients had been treated with persistent, intensive, preserved topical antimicrobials. Most of these topical medications contain benzalkonium chloride as preservative, which is known to disrupt cell walls by emulsifying membrane lipids. ${ }^{9}$ It also decreases epithelial microvilli, reduces corneal wetting, and inhibits cell motility and surface healing. It is probable that $\mathrm{pH}$ balance had been altered owing to the interaction of multiple medications, and in the presence of a compromised ocular surface and a nonhealing epithelial defect, could result in precipitation, with the appearance of corneal deposits.

As ofloxacin is not available unpreserved, it was stopped in order to reduce the insult of multiple 
preservatives on the already compromised ocular surface, and was substituted with unpreserved antimicrobials in order to promote epithelialisation, and reduce corneal and conjunctival toxicity. In particular, some patients had been treated with topical gentamicin before presentation, which further compromised the ocular surface.

The avoidance of prolonged and intensive multiple topical therapy containing preservatives should promote ocular surface stability and help to reduce the incidence of precipitation of crystalline corneal deposits.

Discontinuation of Ofloxacin and modification of topical therapy should aid the resolution of these deposits in most cases. If deposits persist and prevent epithelialisation, they should be debrided to permit the cornea to epithelialise. In all the presented cases, the cornea epithelialised following cessation of ofloxacin, and removal of the deposits, without any adverse outcome, although some deposits persisted subepithelially (Case 6).

\section{References}

1 Castillo A, Benitez del Castillo JM, Toledano N, Diaz-Valle D, Sayagues O, Garcia-Sanchez J. Deposits of topical norfloxacin in the treatment of bacterial keratitis. Cornea 1997; 16(4): 420-423.

2 Konishi M, Yamada M, Mashima Y. Corneal ulcer associated with deposits of norfloxacin. Am J Ophthalmol 1998; 125: 258-260.

3 Eiferman RA, Snyder JP, Nordquist RE. Ciprofloxacin microprecipitates and macroprecipitates in the human corneal epithelium. J Cataract Refract Surg 2001; 27: 1701-1702.

4 Claerhout I, Kestelyn P, Meire F, Remon JP, Decaestecker T, Van Bocxlaer J. Corneal deposits after topical use of ofloxacin in two children with vernal keratoconjuctivitis. $\mathrm{Br} J$ Ophthalmol 2003; 87: 646.

5 Sinnaeve BA, Decaestecker TN, Claerhout IJ, Kestelyn P, Remon JP, Van Bocxlaer JF. Confirmation of ofloxacin precipitation in corneal deposits by microbore liquid chromatography-quadrupole time-of-flight tandem mass spectrometry. J Chromatogr B 2003; 785(1): 193-196.

6 Awwad ST, Haddad W, Wang MX, Parmar D, Conger D, Cavanagh DH. Corneal intrastromal gatifloxacin crystal deposits after penetrating keratoplasty. Eye Contact Lens Sci Clin Pract 2004; 30(3): 169-172.

7 Firestone BA, Dickason MA, Tran T. Solubility characteristics of three fluoroquinolone ophthalmic solutions in an in vitro tear model. Int J Pharm 1998; 164: 119-128.

8 Scuderi AC, Paladino GM, Marino C, Trombetta F. In vitro toxicity of netilmicin and ofloxacin on corneal epithelial cells. Cornea 2003; 22(5): 468-472.

9 Dart J. Corneal toxicity: the epithelium and stroma in iatrogenic and factitious disease. Eye 2003; 17(8): 886-892. 